\title{
Relationship between increase in astrocytic GLT-1 glutamate transport and late-LTP
}

\author{
Juan D. Pita-Almenar, ${ }^{1}$ Shengwei Zou, ${ }^{2}$ Costa M. Colbert, ${ }^{3}$ and Arnold Eskin ${ }^{4}$ \\ Department of Biology and Biochemistry, University of Houston, Houston, Texas 77204-5001, USA
}

\begin{abstract}
$\mathrm{Na}^{+}$-dependent high-affinity glutamate transporters have important roles in the maintenance of basal levels of glutamate and clearance of glutamate during synaptic transmission. Interestingly, several studies have shown that basal glutamate transport displays plasticity. Glutamate uptake increases in hippocampal slices during early long-term potentiation (E-LTP) and late long-term potentiation (L-LTP). Four issues were addressed in this research: Which glutamate transporter is responsible for the increase in glutamate uptake during L-LTP? In what cell type in the hippocampus does the increase in glutamate uptake occur? Does a single type of cell contain all the mechanisms to respond to an induction stimulus with a change in glutamate uptake? What role does the increase in glutamate uptake play during L-LTP? We have confirmed that GLT-1 is responsible for the increase in glutamate uptake during L-LTP. Also, we found that astrocytes were responsible for much, if not all, of the increase in glutamate uptake in hippocampal slices during L-LTP. Additionally, we found that cultured astrocytes alone were able to respond to an induction stimulus with an increase in glutamate uptake. Inhibition of basal glutamate uptake did not affect the induction of L-LTP, but inhibition of the increase in glutamate uptake did inhibit both the expression of L-LTP and induction of additional LTP. It seems likely that heightened glutamate transport plays an ongoing role in the ability of hippocampal circuitry to code and store information.
\end{abstract}

$\mathrm{Na}^{+}$-dependent high-affinity glutamate transporters have important roles in the maintenance of basal levels of glutamate and clearance of glutamate during synaptic transmission (Huang and Bergles 2004; Tzingounis and Wadiche 2007). Glutamate transporters also appear to have important roles in synaptic plasticity and memory formation (Maleszka et al. 2000; Katagiri et al. 2001; Levenson et al. 2002; Yang et al. 2005; Tzingounis and Wadiche 2007; Omrani et al. 2009; Scimemi et al. 2009). Interestingly, several studies have shown that glutamate transport itself displays plasticity as it is regulated in both vertebrates and invertebrates during synaptic plasticity and memory formation (Levenson et al. 2000, 2002; Shen and Linden 2005; PitaAlmenar et al. 2006). In hippocampal brain slices, an increase in glutamate uptake by $\sim 70 \%$ parallels the time course of the early (E-LTP) and late (L-LTP) phases of long-term potentiation (LTP). The parallel between the time course of LTP and the increase in glutamate uptake suggests that the increase in glutamate uptake has an important role in LTP.

Four issues were addressed in this research. Which glutamate transporter is responsible for the increase in glutamate uptake during L-LTP? In what cell type in the hippocampus does the increase in glutamate uptake occur? Does a single type of cultured cell (e.g., astrocytes) contain all the mechanisms to respond to an induction stimulus with an increase in glutamate uptake? What role does the increase in glutamate uptake play during L-LTP?

Present addresses: 'Department of Neurobiology \& Anatomy, University of Texas Medical School, Houston, TX 77030, USA; ${ }^{2}$ Department of Molecular Physiology and Biophysics, Baylor College of Medicine, Houston, TX 77030, USA; ${ }^{3}$ Smart Logic, Inc., Emerald Hills, CA, 94062, USA

${ }^{4}$ Corresponding author

E-mail eskin@uh.edu

Article is online at http://www.learnmem.org/cgi/doi/10.1101/lm.023259.111.
In mammals, basal glutamate uptake in the brain is maintained by five different glutamate transporters (Danbolt 2001). The main glutamate transporters identified in the hippocampus are GLT-1, GLAST, and EAAC1 (Rothstein et al. 1994). Under basal conditions, GLT-1 is expressed in astrocytes and in CA3 presynaptic neuronal terminals of the hippocampus (Rothstein et al. 1994; Chen et al. 2002; Furness et al. 2008). EAAC1, a primarily neuronal glutamate transporter, is expressed in pyramidal cells and in GABAergic interneurons of the hippocampus (Rothstein et al. 1994; Conti et al. 1998). GLAST is only found in astrocytes (Rothstein et al. 1994).

To investigate which cell type and glutamate transporter in the hippocampus are responsible for the increase in glutamate uptake, it is important to distinguish between experiments that investigate the increase in glutamate uptake from experiments that investigate the basal level of glutamate uptake. For example, some cells in hippocampal slices express GLT-1 basally during E-LTP, but GLT-1 is not responsible for the increase in glutamate uptake that occurs during E-LTP. EAAC1 appears to be responsible for the increase in glutamate uptake during E-LTP, whereas GLT-1 appears to be responsible for the increase in glutamate uptake during L-LTP. Therefore, the presence of a basal level of a transporter is not a predictor of the role of that transporter in increases of glutamate transport. The roles of glutamate transporters need to be determined experimentally.

In our earlier studies, we obtained evidence, using Western blots and inhibition of GLT-1 with dihydrokainate (DHK), that GLT-1 was responsible for the increase in glutamate uptake during L-LTP. We have substantially confirmed in this paper that GLT-1 is responsible for the increase in glutamate uptake during L-LTP. The increase of glutamate uptake and GLT-1 in the hippocampus might occur in astrocytes, presynaptic terminals, or other neuronal processes, or some combination of these sites (Chen et al. 2002, 2004; Berger et al. 2005). In our earlier studies, no information was obtained on the cell type responsible for the 
increase in glutamate uptake because glutamate uptake was measured in hippocampal slices, which contain several types of cells (Levenson et al. 2002; Pita-Almenar et al. 2006). In this new research, we found that astrocytes were responsible for much, if not all, of the increase in glutamate uptake in hippocampal slices during L-LTP. Additionally, we found that cultured astrocytes by themselves were able to respond to a chemical induction stimulus (CI) with an increase in glutamate uptake. The increase in glutamate uptake that occurs during L-LTP could have a number of different functions. In fact, the involvement of different transporters during E-LTP (EAAC1) and L-LTP (GLT-1) suggests that the increases in glutamate uptake may have different functions during E-LTP and L-LTP (Pita-Almenar et al. 2006). Overall, we tested in this paper the hypothesis that the increase in glutamate uptake during L-LTP occurs in astrocytes and is due to an increase in GLT-1 in astrocytes. Moreover, we tested the hypothesis that the function of the increase in glutamate uptake is important for the expression of L-LTP and some forms of the induction of LTP.

\section{Results}

\section{Chemical induction of LTP produced an increase in glutamate uptake in hippocampal slices}

Our previous studies demonstrated that glutamate uptake during contextual fear conditioning and during LTP in hippocampal slices exhibited plasticity (Levenson et al. 2002; Pita-Almenar et al. 2006). High-frequency stimulation (HFS) of the Schaffer collateral induced a rapid (early) and persistent (late) increase in glutamate uptake in area CA1 of hippocampal slices. The increase in glutamate uptake in hippocampal slices during the late time domain of LTP, L-LTP, appeared to be mediated by GLT-1, whereas the increase in glutamate uptake during the early time domain of LTP, E-LTP, appeared to be mediated by EAAC1 (Pita-Almenar et al. 2006). What type of glutamate transporter and cell type are involved in the increase in glutamate uptake during L-LTP? To test the hypothesis that an LTP induction stimulus can increase GLT-1 transporter activity in astrocytes, a chemical LTP induction stimulus was used as an analog of the induction of LTP. Chemical induction of LTP (forskolin $+0 \mathrm{Mg}^{2+}$ ) is well-established and is frequently used to maximize the number of synapses, cells, or slices that can be experimentally treated (Liao et al. 1992; Bolshakov et al. 1997; Sokolov et al. 2002; Otmakhov et al. 2004; Boehm et al. 2006; Kopec et al. 2006). cAMP analogs by themselves can induce GLT-1 in astrocytes, but this effect of cAMP requires days of treatment, whereas the effects of forskolin plus $0 \mathrm{Mg}^{2+}$ occur after only 20 min of treatment with CI (Schlag et al. 1998). The $0 \mathrm{Mg}^{2+}$ of the CI stimulus is likely to increase intracellular $\mathrm{Ca}^{2+}$. It is wellknown that $0 \mathrm{Mg}^{2+}$ increases spontaneous activity in neurons and the spontaneous generation, duration, and extension of $\mathrm{Ca}^{2+}$ waves in astrocytes (Stout and Charles 2003).

Treatment of hippocampal slices in an interface chamber with CI $\left(50 \mu \mathrm{M}\right.$ forskolin and $\left.0 \mathrm{Mg}^{2+}, 20 \mathrm{~min}\right)$ produced E-LTP and L-LTP of the CA3-CA1 synaptic response $(N=5$ rats) (Fig. 1A). Also, CI significantly increased glutamate uptake in slices during the late time domain of LTP $(92 \pm 16 \%, N=5, P<0.01)$ (Fig. 1B) as well as during the early time domain of LTP (74 $\pm 19 \%$, $N=5, P<0.05$ ) (Fig. 1B). Given that high-affinity glutamate transporters use the $\mathrm{Na}^{+}$gradient to transport glutamate, we tested whether the increase in glutamate uptake produced by CI was $\mathrm{Na}^{+}$-dependent. Removal of extracellular $\mathrm{Na}^{+}$during measurement of glutamate uptake decreased the basal level of glutamate uptake and eliminated the increase in glutamate uptake produced by CI (one-way ANOVA $F_{(5,18)}=46.01 P<0.01$ ) (Fig. 1B). The data for the increase in glutamate uptake in slices produced by CI can be corrected for the $\mathrm{Na}^{+}$-independent uptake of glutamate (Fig.
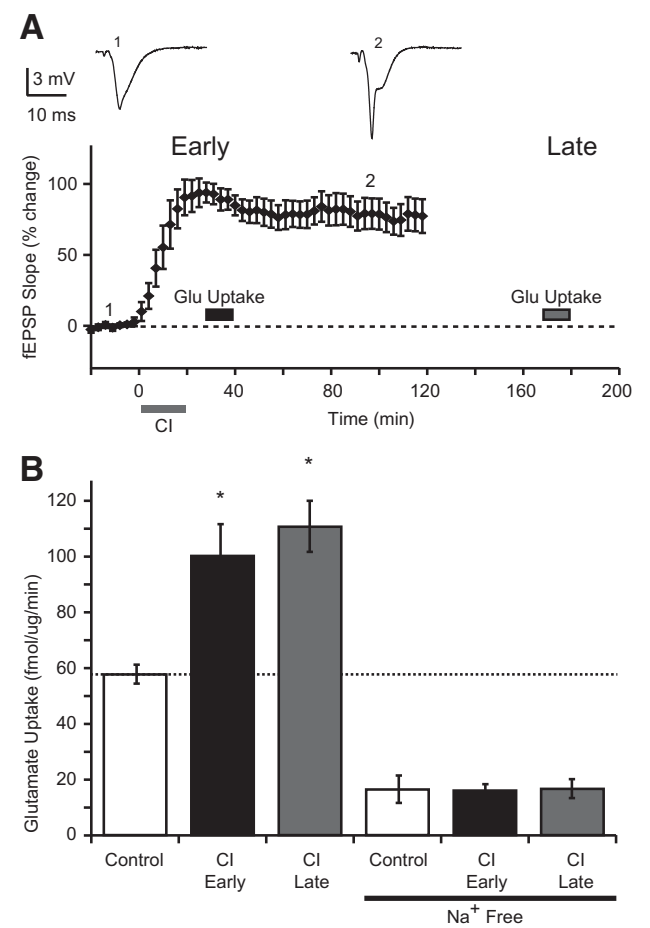

Figure 1. Exposure of hippocampal slices to chemical induction $(\mathrm{Cl})$ induced short-term and long-term increases in glutamate uptake. $(A)$ Forskolin in $\mathrm{Mg}^{2+}$-free ACSF (Cl, chemical induction) was applied for $20 \mathrm{~min}$ to slices in an interface chamber. After $20 \mathrm{~min}$ of baseline recording of field excitatory post-synaptic potentials (fEPSPs) of the Schaffer collateral synapse, fEPSPs were recorded at 5-min intervals. $\mathrm{Cl}$ produced short-term and long-term potentiation (LTP) that lasted for at least 120 min. fEPSP recordings in the interface chamber were stopped at $120 \mathrm{~min}$ after HFS to transfer slices to submerged chambers for whole-cell recordings. The fEPSP traces on the top of Figure 1A were taken at the times corresponding to the numbers on the bottom of the graph of Figure 1A. (B) Once the early (30 min after $\mathrm{Cl})$ and late (180 min after Cl) time domains of LTP were reached, slices were transferred to a submerged chamber to measure glutamate uptake during the times shown on the bottom of Figure 1A. Cl caused a significant increase in glutamate uptake in CA1 during both early and late phases of LTP. CI mimicked the effects of high-frequency stimulation (HFS) on glutamate uptake (Pita-Almenar et al. 2006). Glutamate uptake and the increases in glutamate uptake produced by $\mathrm{Cl}$ were $\mathrm{Na}^{+}$-dependent. Data were analyzed using a one-way ANOVA $\left(F_{(5,18)}=46\right)$, and post-hoc analysis was performed with Tukey's multiple comparison tests. Data are mean \pm SEM. $\left(^{*}\right)$ Significant difference from control, $P<0.01$.

$1 \mathrm{~B}, \mathrm{Na}^{+}$-free data) by subtracting the $\mathrm{Na}^{+}$-independent glutamate uptake from the control and CI-induced uptake. The increase in glutamate uptake in slices produced by $\mathrm{CI}$ and corrected for $\mathrm{Na}^{+}$-dependent uptake was $104.0 \pm 33.7 \%$ during the early and $127.8 \pm 28.6 \%$ during the late time domain of LTP. Thus, CI mimicked HFS in producing E-LTP and L-LTP as well as increases in $\mathrm{Na}^{+}$-dependent glutamate uptake (Pita-Almenar et al. 2006). These results confirm that an induction stimulus can increase glutamate uptake during E-LTP and L-LTP.

\section{$\mathrm{Cl}$ produced an increase of glutamate transporter current in astrocytes in hippocampal slices during late, but not early, LTP}

Discovery of the cell types in which the change in glutamate transport occurs is a necessary step toward defining the cell type and glutamate transporter responsible for the late increase in glutamate transport. The activity of glutamate transporters in 
astrocytes was analyzed by applying a constant concentration of caged glutamate to hippocampal slices and then measuring the amplitude of glutamate transporter current in astrocytes triggered when glutamate was rapidly uncaged. Astrocytes in the CA1 stratum radiatum were identified by their small cell bodies, low input resistance $(10-60 \mathrm{M} \Omega$ ), and negative resting membrane potentials $(\sim-80 \mathrm{mV})$. Cells that did not have low input resistances and hyperpolarized membrane potentials were not included in the analysis (Matthias et al. 2003). In the presence of glutamate receptor and $\mathrm{Na}^{+}$channel blockers (see Materials and Methods), uncaging of glutamate by flash photolysis induced a rapid inward current in astrocytes (Fig. 2A). No current was elicited when the preparation was flashed with UV light in the absence of caged glutamate (Fig. 2A). Furthermore, the current induced by uncaging glutamate was blocked by DL-threo-beta-benzyloxyaspartic acid (TBOA; $100 \mu \mathrm{M}$ ) (Fig. 2A), a selective inhibitor of glutamate transporters that was previously shown to block increases in glutamate uptake in hippocampal slices during LTP (Pita-Almenar et al. 2006). Additionally, the I-V plot of the current elicited by caged glutamate displayed voltage dependence and inward rectification characteristic of glutamate transporter currents as seen by others (Fig. 2B; Bergles and Jahr 1997). Therefore, the properties of the inward astrocytic current induced by uncaging of glutamate are those of currents associated with glutamate transporters.

As predicted by our hypothesis, CI produced a significant increase $(144 \pm 23 \%, P<0.001)$ in transporter current in astrocytes during the late time domain of LTP (control: $N=25$ cells; experimental: $N=24$ cells) (Fig. $2 \mathrm{C}$, Late), but $\mathrm{CI}$ had no effect ( $P=$ $0.69)$ on the astrocytic transporter current measured during the early time domain of LTP (control: $N=11$ cells; experimental: $N=10$ cells) (Fig. 2C, Early). The amplitudes of control glutamate transporter currents measured during the early time domain were not significantly different from control currents measured during the late time domain (Fig. 2C). No changes in the resting membrane potential (control: $-77.9 \pm 1.6 \mathrm{mV}, N=25$ cells; experimental: $-78.1 \pm 1.0 \mathrm{mV}, N=24$ cells, $P=0.91$ ) or cell input resistance (control: $39.0 \pm 7.7 \mathrm{M} \Omega, N=25$ cells; experimental: $26.7 \pm 4.9 \mathrm{M} \Omega, N=24$ cells, $P=0.17$ ) due to CI were observed during the late time domain. The increase in the glutamate transporter current observed in astrocytes in hippocampal slices during the late time domain (Fig. 2C) supports our hypothesis that the late increase in glutamate uptake occurs in astrocytes. These are the first results that directly link astrocytes with the increase in glutamate uptake during L-LTP. The lack of an increase in glutamate transporter current in astrocytes during the early time domain (Fig. 2C) indicated that the early increase in glutamate transporter activity, which appeared to be mediated by EAAC1 (Pita-Almenar et al. 2006), did not occur in astrocytes. Thus, the early increase in glutamate uptake appears to occur in neurons, and EAAC1 does not appear to be present in astrocytes (see Fig. 4, below; Rothstein et al. 1994). In the experiment shown in Figure 1B, CI produced an increase in glutamate uptake in hippocampal slices during both early and late time domains. In Figure 1, glutamate uptake was measured in all cells in the slice, some of which had EAAC1, whereas in Figure 2 glutamate transporter current was selectively measured in astrocytes. The results of Figure 2 confirm our previous results that different types of transporters were responsible for changes in glutamate uptake during different time domains (Pita-Almenar et al. 2006).

\section{GLT-1 mediates the increase in glutamate transporter current in astrocytes in slices}

Our previous results indicate that changes in membrane expression of glutamate transporter GLT-1 mediates the increase in glutamate uptake occurring in slices during the late phase of LTP
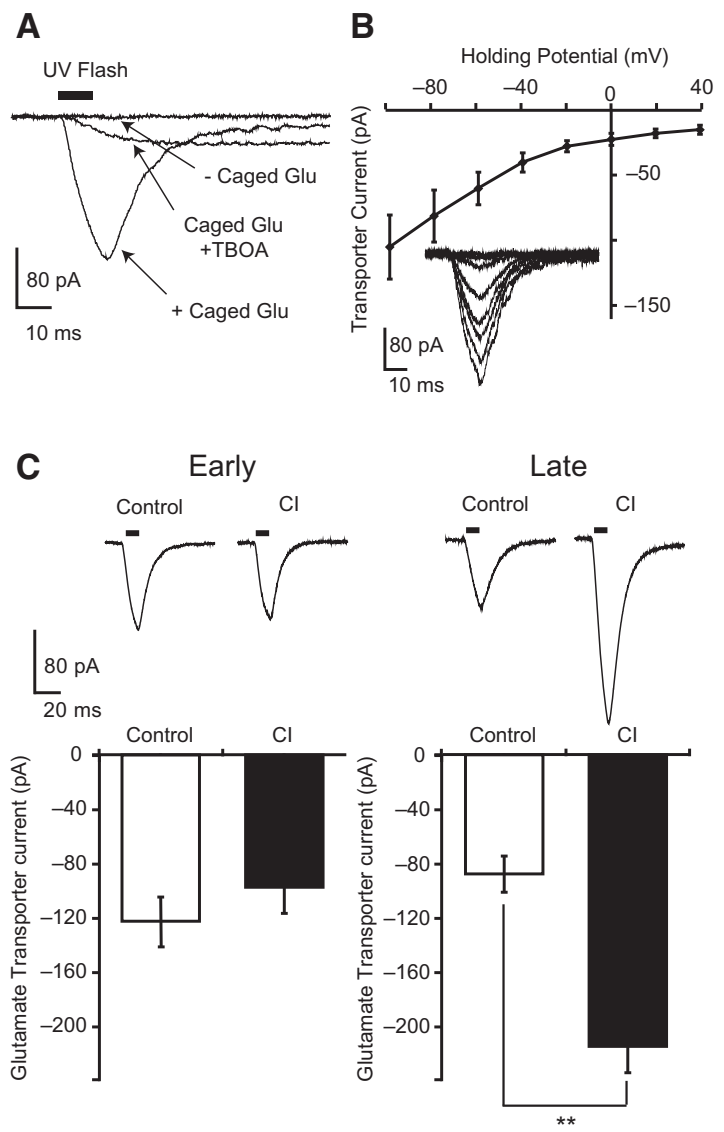

Figure 2. $\mathrm{Cl}$ produced an increase in glutamate transporter currents in astrocytes during the late phase but not during the early phase of LTP. (A) During whole-cell recordings of astrocytes in the CA1 area of hippocampal slices, a 10-msec UV light flash (dark bar) in the presence of 4-Methoxy-7-nitroindolinyl (MNI)-caged glutamate induced a rapid, transient inward current. 6,7-dinitroquinoxaline-2,3-dione (DNQX), DL-2-amino-5-phosphonopentanoic acid (APV), $(5 S, 10 R)-(+)-5$ -Methyl- 10, 11-dihydro- 5H-dibenzo[a,d]cyclohepten- 5,10 -imine maleate (MK801), and tetrodotoxin (TTX) were present during measurements of currents. The transient inward current resulting from uncaging glutamate was blocked by the glutamate transport blocker TBOA. A UV light flash without caged glutamate present did not induce a transient transporter current. (B) The peak amplitude of the flash-induced glutamate transporter current in astrocytes displayed the characteristic inward rectification of glutamate transporter currents. (Inset) Representative recordings of transporter current at different holding voltages. (C) $\mathrm{Cl}$ induced a significant increase in transporter current in astrocytes during the late phase of LTP, but $\mathrm{Cl}$ did not significantly affect transporter current during the early phase of LTP. Transporter currents were measured 30-60 min (early) or 130-210 min (late) after exposure of slices to $\mathrm{Cl}$ for $20 \mathrm{~min}$. Representative glutamate transporter currents in control and experimental astrocytes in hippocampal slices are shown above summaries of data. Dark bars above the recordings of current span the time of the UV flash. Data were analyzed using a one-way ANOVA $\left(F_{(3,66)}=13.0\right)$, and post-hoc analysis was performed with Tukey's multiple comparison tests. (**) Significant difference from control, $P<0.001$. Error bars are \pm SEM.

(Pita-Almenar et al. 2006). If the increase in astrocytic glutamate transporter current were mediated by GLT-1, then the amount of transporter current inhibited by DHK should be larger in astrocytes during L-LTP. To test this, transporter currents were measured in individual astrocytes in hippocampal control and experimental slices $3 \mathrm{~h}$ after exposure to vehicle or CI, respectively. Currents were measured during the $10 \mathrm{~min}$ before and $10 \mathrm{~min}$ after washing in 
DHK $(300 \mu \mathrm{M})$ (Fig. 3A,B). The basal GLT-1 component of astrocytic transporter current of control slices was $-32.8 \pm 14.1 \mathrm{pA}$ [control current - (control + DHK current)] $(N=14$ cells) (Fig. 3A, light hatching). The inhibition of basal transporter current by DHK observed in control slices of this experiment ( $40 \pm 15 \%$ inhibition) (Fig. 3A) was similar to the level of inhibition produced by DHK upon synaptically generated transporter currents $(30 \%-$ 40\%) (Bergles and Jahr 1997), flash photolysis-generated currents (56\%) (Huang et al. 2004), and basal glutamate uptake ( 50\%) (Pita-Almenar et al. 2006). CI significantly increased the astrocytic transporter current by $127 \pm 15 \%(N=14$ cells, $P<0.01)$. The GLT-1 component of astrocytic transporter current of CI-treated slices was $-116.2 \pm 13.7 \mathrm{pA}$ [CI current $-(\mathrm{CI}+\mathrm{DHK}$ current $)]$ ( $N=14$ cells) (Fig. 3B, dark hatching). Thus, CI treatment increased the GLT-1 component of the astrocytic glutamate transporter current sensitive to DHK by $254 \%$ (compare light vs. dark hatching in Fig. 3A,B).

DHK appeared to inhibit most, if not all, of the increase in transporter current produced by CI (Fig. 3; compare "CI + DHK" with "control + DHK"). The portion of the increase in astrocytic current that appeared not to be inhibited by DHK was $<20 \%$. Similarly, others have observed a DHK-independent GLT-1 current (Bergles and Jahr 1997; Huang et al. 2004). Therefore, the in-

A

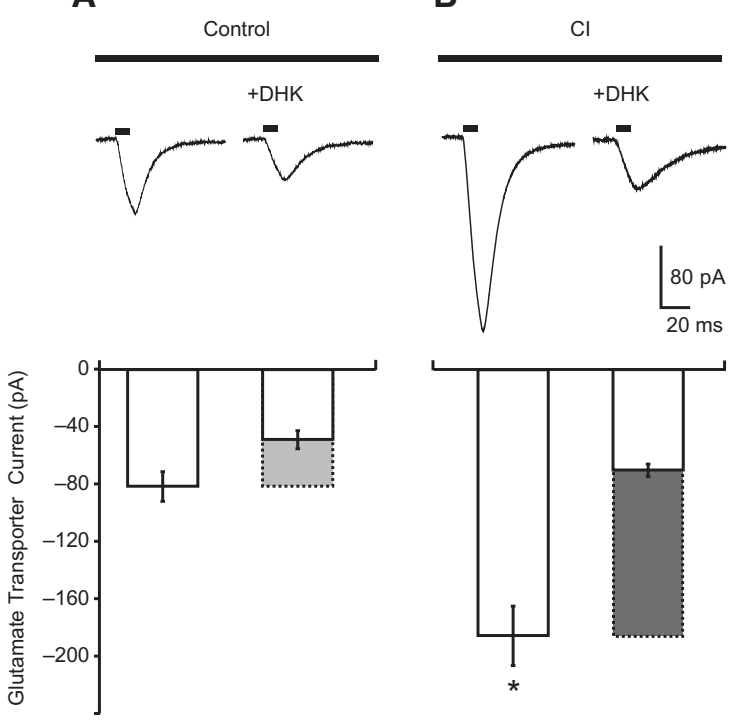

Figure 3. The increase in astrocytic transporter current produced by $\mathrm{Cl}$ was inhibited by DHK. $(A)$ Transporter currents were recorded from individual control astrocytes for $3 \mathrm{~h}$ after the slices were exposed to vehicle for $20 \mathrm{~min}$. Short dark bars over the current traces represent the duration of the UV light flash. Representative traces of recordings of individual control astrocytes during $10 \mathrm{~min}$ before (left trace) and then $10 \mathrm{~min}$ after washing in DHK (right) are shown in the top of the figure. Summaries of data are shown underneath the recordings. DHK inhibited glutamate-induced transporter currents. The amount of basal current inhibited by DHK is the lightly shaded area of the bar. $(B)$ Transporter currents were recorded from individual astrocytes $3 \mathrm{~h}$ after the slices were exposed to $\mathrm{Cl}$ for $20 \mathrm{~min}$. Recordings were made $10 \mathrm{~min}$ before (left side) and $10 \mathrm{~min}$ after (right side) exposure of slices to DHK. Representative traces are shown at the top and summary of the results are shown at the bottom of the figure. $\mathrm{Cl}$ produced an increase in astrocytic transporter current of $127 \%$ (Cl vs. control). Most of the current increased by Cl was inhibited by DHK (the dark area of the bar on the right side of Fig. 3B). Thus, the transporter current in astrocytes appears to be due to GLT-1 which is inhibited by DHK. Data were analyzed using a one-way ANOVA $\left(F_{(3,52)}=\right.$ 23.6), and post-hoc analysis was performed with Tukey's multiple comparison tests. $(*)$ Significant difference, $P<0.01$. Error bars are \pm SEM. crease in astrocytic glutamate transporter current during the late time domain produced by CI was due largely, if not solely, to an increase in activity of a GLT-1-type glutamate transporter. These results support the hypothesis that the increase in glutamate uptake during L-LTP was due to an increase in GLT-1 in astrocytes.

\section{High-frequency stimulation elicited an increase in astrocytic transporter current in hippocampal slices}

Does HFS mimic the effect of CI upon the late transporter current in astrocytes? These experiments were performed similarly to those using CI, except experimental slices received HFS (Pita-Almenar et al. 2006). As with CI, HFS produced a significant increase in astrocytic transporter current during the late time domain ( $35 \pm 3 \%, N=10$ cells, $P<0.05$ ) but not during the early time domain ( $13 \pm 1 \%, N=11$ cells). The ability of HFS to mimic the effect of $\mathrm{CI}$ on astrocytic transporter current validates the use of CI as an analog of HFS and strengthens the result that LTP induction stimuli can increase astrocytic transporter currents.

\section{$\mathrm{Cl}$ can increase glutamate uptake in cultures of astrocytes in the absence of other types of cells}

In our previous experiments using hippocampal slices, the contribution of nonglial cells to the changes observed in glutamate transporter activity is not known. Moreover, the target cells responding to CI and HFS are not known. To test whether the increase in activity of glutamate transporters requires only astrocytes, we investigated the regulation of glutamate transporters in primary cultures of hippocampal astrocytes in the absence of neurons. Primary cultures of astrocytes were prepared following techniques of Engele's lab (Franke et al. 1998; Schluter et al. 2002; Lehmann et al. 2009). Cultures of astrocytes were generated from dissociation of hippocampal cells from 2-d-old rats. Differentiation of astrocytes and removal of neurons were a result of growth factors in the media and re-plating cultures several times prior to use (see Materials and Methods). All cultures used in our studies contained only differentiated astrocytes. This was established by the following findings. All DAPI (nuclear)-stained cultured cells were also stained by GFAP (glial) antibodies (Fig. 4A), and the DAPI-stained cells exhibited the typical morphology of astrocytes. Also, all the cultured cells were stained by GLT-1 (transporter) antibody and to a lesser extent by GLAST (transporter) antibodies. None of the cultured cells were stained by the neuronal EAAC1 (transporter) antibodies. Control staining experiments ruled out staining by secondary antibodies (not shown). The immunocytochemical studies were confirmed by Western blot analysis (Fig. 4B). GLT-1 and GLAST antibodies stained appropriate molecular weight bands on Western blots of proteins from the cultured astrocytes, whereas no proteins were stained by the EAAC1 antibody (Danbolt et al. 1992). Thus, the cultured astrocytes have the properties of differentiated astrocytes in situ.

Initially, we tested whether glutamate uptake was increased by $\mathrm{CI}$ in cultured astrocytes. CI for 20 min produced a significant, $53 \pm 8 \%$ increase in glutamate uptake $4 \mathrm{~h}$ after exposure of cultures to CI (CI vs. control, $N=8, P<0.001$ ) (Fig. 5A). This effect of $\mathrm{CI}$ on cultured astrocytes was significantly greater than the effect of forskolin alone for $20 \mathrm{~min}$ and glutamate uptake measured $4 \mathrm{~h}$ later $(18 \pm 7 \%, N=4, P<0.05)$ (see Fig. 5B in Pita-Almenar et al. 2006). Therefore, CI can increase glutamate uptake in cultures of astrocytes in the absence of other types of cells, and forskolin itself elicits a much smaller effect on glutamate uptake than forskolin plus $0 \mathrm{Mg}^{2+}(\mathrm{CI})$.

Removal of $\mathrm{Na}^{+}$during the measurement of glutamate uptake reduced control uptake by $\sim 60 \%$ and revealed that the increase in glutamate uptake in cultured astrocytes produced by 


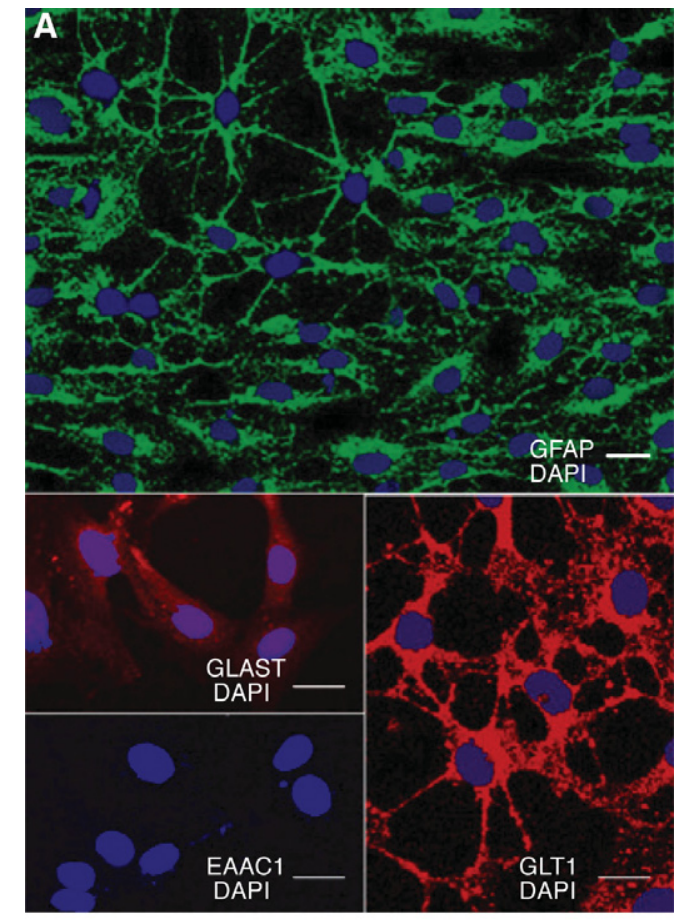

B

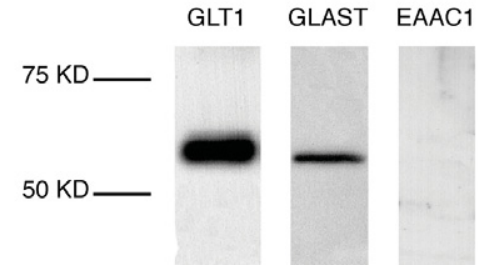

Figure 4. Primary cultures of hippocampal astrocytes express both GLT-1 and GLAST glutamate transporters. (A) Cultures of astrocytes were generated from dissociation of hippocampal cells from 2-d-old rats according to the technique of Engele's lab (Schluter et al. 2002; Lehmann et al. 2009). The cells were exposed for 3-5 d to culture media with growth factors (see Materials and Methods). All cultured cells were stained by DAPI (blue), a nuclear stain, and by GFAP (green), a glial marker. Thus, all cells in the culture appeared to be astrocytes. Additionally, all cells in culture were stained by antibodies to GLT-1 (red) and, to a lesser extent, by antibodies to GLAST (red). The cultured cells were not stained by antibodies to EAAC1. The cells stained by GFAP and GLT-1 expressed the morphology of astrocytes. Thus, the cultures contained only cells with characteristics of differentiated astrocytes. The white scale bar denotes $20 \mu \mathrm{m}$. (B) Western blots of astrocytic protein confirmed the results of immunocytochemistry. The blots of cultured cells were stained strongly by antibodies to GLT-1, more weakly stained by antibodies to GLAST, and were not stained at all by antibodies to EAAC1.

CI was mediated by $\mathrm{Na}^{+}$-dependent transporters (Fig. 5B). The data for the increase in uptake produced by $\mathrm{CI}$ in Figure $5 \mathrm{~A}$ can be corrected for the $\mathrm{Na}^{+}$-independent uptake of glutamate by subtracting the $\mathrm{Na}^{+}$-independent glutamate uptake from the control and CI-induced uptake in Figure 5A. The increase in glutamate uptake produced by $\mathrm{CI}$ and corrected for $\mathrm{Na}^{+}$-independent uptake was $87.4 \pm 12.5 \%$. The uncorrected increase in glutamate uptake cited earlier was $53 \pm 8 \%$.

Which glutamate transporter in cultured astrocytes was responsible for the increase in glutamate uptake during L-LTP? To test the role of GLT-1, DHK was applied to both the control and CI-treated cultured astrocytes during measurement of glutamate uptake $(N=8)$ (Fig. 5C). DHK, as in slices, reduced the basal glu- tamate uptake of control astrocytes by $47 \%$. More importantly, DHK completely blocked the increase in glutamate uptake induced by CI treatment $(N=8$, compare control + DHK vs. CI + DHK) (Fig. 5C). Therefore, the entire increase in glutamate uptake of cultured astrocytes appears to be due to an increase in GLT-1 in astrocytes. Other transporters present in astrocytes insensitive to
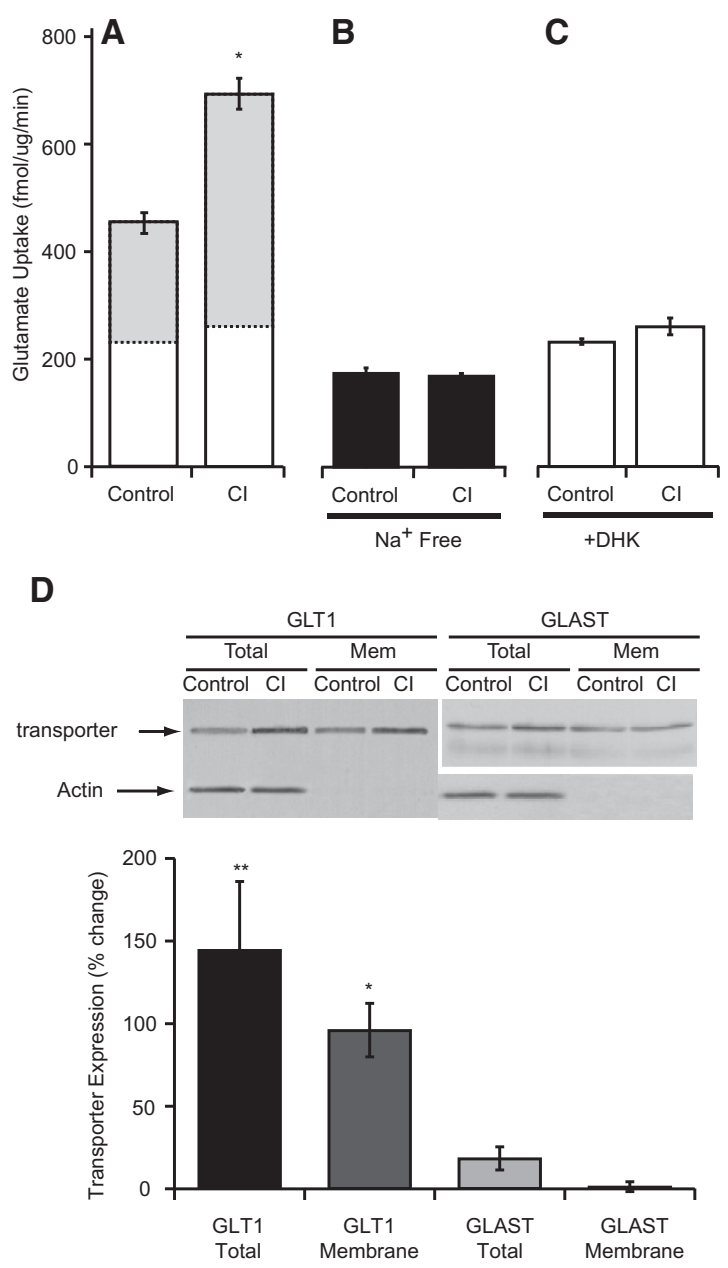

Figure 5. Chemical induction increased glutamate uptake and expression of GLT-1 in primary cultured hippocampal astrocytes. (A) Cl significantly increased glutamate uptake in primary cultured astrocytes $4 \mathrm{~h}$ after treatment with $\mathrm{Cl}$ for $20 \mathrm{~min}$. Lightly shaded areas represent the fraction of glutamate uptake that was inhibited by DHK. The increase in DHK-sensitive uptake produced by $\mathrm{Cl}$ was $109.7 \pm 23.2 \%$. (B) Glutamate uptake of control and $\mathrm{Cl}$-treated astrocytic cultures was measured in $\mathrm{Na}^{+}$-free conditions. $\mathrm{Na}^{+}$-free conditions completely abolished the effect of $\mathrm{Cl}$ on glutamate uptake and reduced basal glutamate by $\sim 60 \%$. (C) DHK inhibited glutamate uptake in both control and $\mathrm{Cl}$-treated astrocytes. The entire increase in glutamate uptake due to $\mathrm{Cl}$ was inhibited by DHK (compare control + DHK vs. $\mathrm{Cl}+\mathrm{DHK}$ ). Therefore, the increase in glutamate uptake produced by $\mathrm{Cl}$ appears to be due to an increase in GLT-1. Data were analyzed using a one-way ANOVA $\left(F_{(2,11)}=20.4\right)$, and post-hoc analysis was performed with Tukey's multiple comparison tests. $\left({ }^{*}\right)$ Significant difference, $P<0.01$. (D) Representative Western blots of transporter protein from total protein and plasma membrane fractions obtained by biotinylation are shown above the summary of results obtained by densitometry. $\mathrm{Cl}$ produced significant increases in levels of GLT-1 in the total protein fraction $(145 \%)$ and in levels of GLT-1 in the plasma membrane fraction (96\%). GLAST levels in total and plasma membrane fractions were not significantly affected by $\mathrm{Cl}$. Data were analyzed using a one-way ANOVA $\left(F_{(4,26)}=11.9\right)$ with Tukey's multiple comparison tests. $\left({ }^{*}\right) P<0.01,\left({ }^{* *}\right)$ $P<0.001$. Error bars are \pm SEM. 
DHK (such as GLAST) did not appear to contribute to the increase in glutamate uptake during L-LTP.

To directly confirm the role of GLT- 1 in the increase in glutamate uptake, the effect of CI on levels of GLT-1 in cultured astrocytes was investigated. Astrocytic cultures were treated with CI, and $4 \mathrm{~h}$ later, levels of GLT- 1 and GLAST transporters in the membrane and total protein fractions were measured by biotinylation and Western blot analysis (Fig. 5D). CI significantly increased the expression of both total and membrane levels of GLT-1 (total: $145 \pm 42 \%, N=5, P<0.05$; membrane: $96 \pm 16 \%, N=7, P<$ $0.01)$. It is worth noting that the increase in DHK-sensitive glutamate uptake of cultured astrocytes (109 $\pm 23 \%$ ) (Fig. 5A, hatched bars) was similar to the increase in GLT-1 in the membrane (96 \pm 16\%) (Fig. 5D). Therefore, an increase in GLT-1 appears to be responsible for the increase in glutamate uptake in astrocytes because DHK inhibited the increase in glutamate uptake in astrocytes and CI increased the level of GLT-1 in astrocytes. Moreover, cell types other than astrocytes were not required for the effect of CI on GLT-1 and glutamate uptake. Total or membrane levels of GLAST in astrocytic cultures were not affected by CI during L-LTP $(N=5, P>$ 0.05) (Fig. 5D).

CI produced a large (145\%) increase in GLT-1 in the total protein fraction from astrocytes (Fig. 5D). An increase in GLT-1 in the total membrane fraction indicates that the change in GLT-1 in the plasma membrane was not due to a shift of GLT-1 from a pool of GLT-1 already present in astrocytes to the membrane. Rather, the large increase in GLT-1 in the total membrane fraction indicates that additional GLT-1 was due to new protein synthesis of GLT-1. This possibility of new synthesis of GLT-1 is consistent with our earlier results showing that the late increase in glutamate uptake required transcription and translation (Pita-Almenar et al. 2006). Therefore, the increase in glutamate uptake may involve transcription and translation of GLT-1, perhaps along with some trafficking steps that could account for the delayed, late increase in glutamate uptake dependent on GLT-1. Alternatively, the synthesis of some protein(s) other than GLT-1 may be necessary for the increase in glutamate uptake during L-LTP (Zou et al. 2011).

\section{Inhibition of the increase in GLT-1 during L-LTP reduced expression of LTP via accumulation of glutamate and activation of metabotropic receptors}

Our results indicate that GLT-1 plays a role in plasticity during LTP. An increase of GLT-1 activity in astrocytes accompanies L-LTP (Fig. 3, present paper; Fig. 4 in Pita-Almenar et al. 2006), and DHK can completely inhibit the increase in glutamate uptake mediated by GLT- 1 in astrocytes. What role does the increase in GLT-1 play in the expression and in- duction of L-LTP? To investigate the function of the increase in GLT-1, DHK was used to inhibit GLT-1 during the late phase of LTP. DHK $(300 \mu \mathrm{M})$ was perfused through the interface chamber for $20 \mathrm{~min}$ during L-LTP (180 min after HFS) while measuring the percent change of the field excitatory post-synaptic potential (fEPSP) slope (Fig. 6, top traces). DHK had a small effect on the basal fEPSP slope during baseline (compare trace a with trace $b$, $N=5, P>0.05$ ). Inhibition of GLT-1 with DHK during L-LTP reduced the expression of L-LTP by $103 \%$ to a level not significantly different from baseline (compare trace c [L-LTP: $133 \pm 26 \%$ change] with trace d [L-LTP + DHK: $30 \pm 28 \%$ change], $N=7, P<$ 0.01 , one-way ANOVA with Tukey's multicomparison test). Thus, the increase in glutamate uptake appears to be important for regulating the expression of L-LTP.

Considerable evidence suggests that both postsynaptic and presynaptic changes are involved in the expression of LTP in the hippocampus (Kerchner and Nicoll 2008; Enoki et al. 2009;

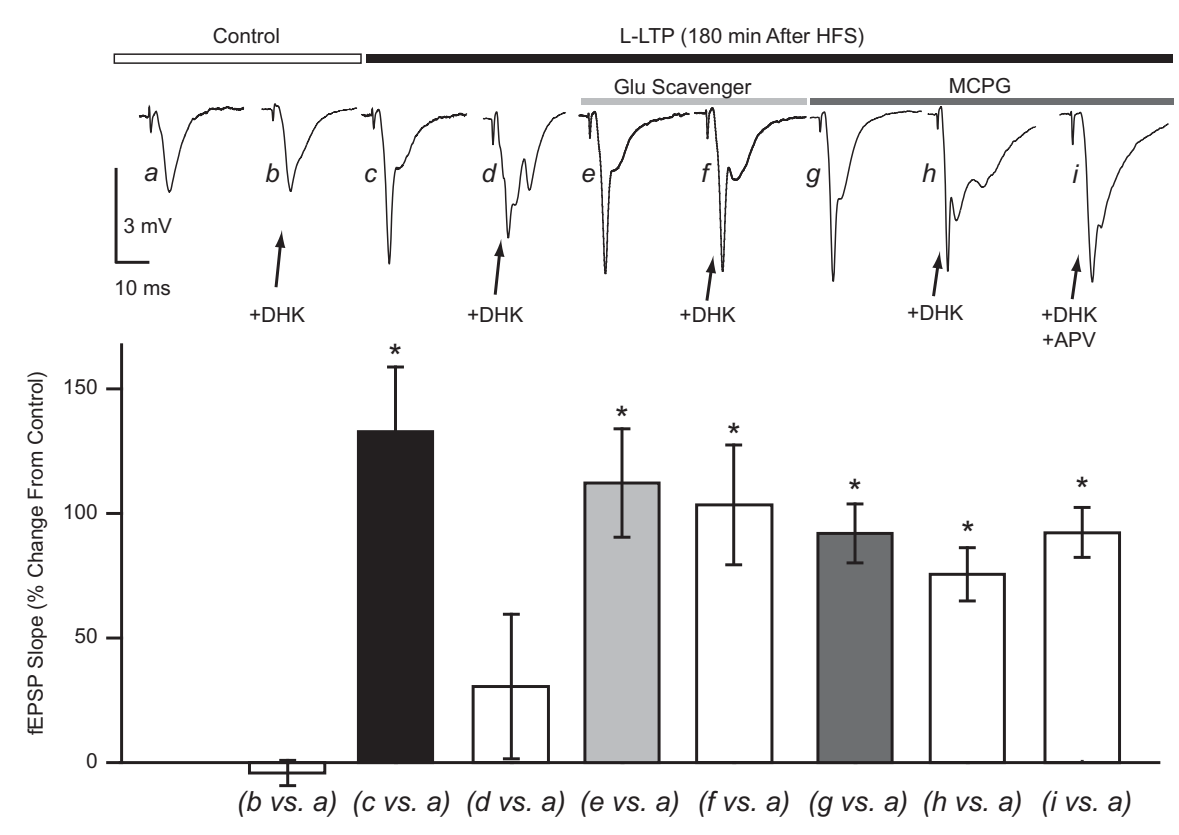

Figure 6. Inhibition of the increase in GLT-1 by DHK blocked the expression of L-LTP. fEPSPS were recorded in CA1 stratum radiatum by stimulating the Schaffer collaterals from CA3. Baseline recordings (trace $a$ ) were obtained for 20 min before HFS. Inhibition of basal glutamate uptake with DHK produced a nonsignificant effect during baseline (trace $b$ ). After baseline recordings, all slices received HFS to induce L-LTP. Traces were quantified 180 min after HFS. fEPSP traces (traces $a$ to $i$ ) shown on the top of the figure were taken from a representative experiment. Summary data are shown in the bottom of the figure. HFS induced L-LTP (trace $c$ vs. trace $a, N=7$ ). DHK prevented the expression of L-LTP when DHK was given during L-LTP (trace $d, N=7$ ). DHK application during L-LTP also led to an increase in duration of fEPSPs and multiple population spikes. A glutamate scavenger (glutamic-pyruvic transaminase $[5 \mathrm{U} / \mathrm{mL}]+$ pyruvate $[2 \mathrm{mM}])$ did not block the expression of L-LTP (trace $e, N=6)$, but the scavenger did reverse the inhibition of expression by DHK (trace $f, N=6$ ). Therefore, the effect of DHK on expression of L-LTP appears to be due to accumulation of glutamate caused by inhibition of GLT-1. Treatment of slices during L-LTP with a nonselective metabotropic glutamate receptor (mGluR) antagonist (RS)- $\alpha$-Methyl-4-carboxyphenylglycine (MCPG, $500 \mu \mathrm{M}$ ) did not affect expression of L-LTP (trace $g, N=5$ ). MCPG reversed the block of expression of L-LTP produced by DHK (trace $h, N=5$ ), but MCPG did not reverse the additional effects of DHK, such as multiple population spikes. APV, a selective NMDA receptor blocker plus MCPG was able to block the increase in duration of the responses as well as the multiple population spikes observed during DHK treatment (compare trace $i$ vs. trace $h, N=5$ ). The inhibition of the increase in GLT-1 during L-LTP by DHK appears to cause an accumulation of glutamate, which then appears to activate metabotropic and NMDA receptors resulting in an inhibition of expression of L-LTP. The reversal of the effect of DHK with the glutamate scavenger (trace $f$ ) indicates that inhibition of expression by DHK is due to an accumulation of glutamate. Thus, the function of the increase in GLT-1 during L-LTP seems to be to prevent inhibition of expression of L-LTP by preventing accumulation of glutamate that activates mGluRs and NMDA receptors. Data were analyzed using a one-way ANOVA $\left(F_{(8,60)}=10.6\right)$ with Tukey's multiple comparison tests. ( $\left.{ }^{*}\right) P<0.01$, significantly different from control. Error bars are \pm SEM. 
Lisman 2009). An increase in release of glutamate by presynaptic terminals has been observed during L-LTP (Zakharenko et al. 2001; Bayazitov et al. 2007). Thus, inhibition of expression of L-LTP by DHK could be the result of an accumulation of extracellular glutamate, which leads to activation of metabotropic glutamate receptors during the late phase of LTP. Does the increase in GLT-1 prevent accumulation of glutamate and activation of mGluRs during L-LTP? We examined this by removing glutamate with a glutamate scavenger (glutamic-pyruvic transaminase [5 $\mathrm{U} / \mathrm{mL}]+$ pyruvate [2 $\mathrm{mM}$ )] ) while the increase in GLT-1 during L-LTP was inhibited with DHK (Fig. 6). Removing extracellular glutamate with the glutamate scavenger alone did not have an effect on L-LTP (compare traces c [L-LTP: $133 \pm 26 \%$ change] and e [L-LTP + Glu Scv: $112 \pm 22 \%$ change], $N=6, P>0.05$, one-way ANOVA with Tukey's multicomparison test). We then perfused DHK during L-LTP in the presence of the glutamate scavenger. The glutamate scavenger reversed the inhibition of expression of L-LTP by DHK (compare $d$ vs. $a$ and $f$ vs. $a, N=6, P<0.001$ ). Inhibition of expression of L-LTP by blocking GLT-1 with DHK was reversed by mimicking the effect of GLT-1 with the glutamate scavenger. These results suggest that removal of glutamate from extracellular space is needed to maintain the expression of L-LTP.

We next investigated whether inhibition of the expression of L-LTP by DHK depends on the activation of metabotropic glutamate receptors, which are known to be responsible for a depotentiation and an increase in inhibitory inputs at the Schaffer collateral synapse (Zho et al. 2002; Huang et al. 2004). The nonselective mGluR inhibitor MCPG $(500 \mu \mathrm{M})$ was applied during L-LTP before and after inhibition of the increase in glutamate uptake with DHK. The metabotropic receptor inhibitor MCPG significantly reduced the effect of DHK on the slope of the fEPSPs during L-LTP $(N=5, P>$ 0.05 ) (compare traces f vs. g in Fig. 6). Therefore, activation of mGluRs is responsible, at least in part, for blocking the expression of L-LTP when the increase in GLT-1 is inhibited.

In addition to reducing the fEPSP slope during L-LTP, the inhibition of the increase in GLT-1 with DHK led to additional effects on the fEPSP traces. These additional effects were characterized by an increase in the duration of fEPSP traces and multiple population spikes after a single electrical stimulation (Fig. 6, trace d). In the presence of the glutamate scavenger, the effects of blocking GLT-1 were not observed (Fig. 6, trace f). This observation suggests that reducing the clearance of glutamate with DHK leads to an increase in duration of fEPSPs and an increase in population spikes. The longer duration of glutamate could lead to a prolonged activation of NMDA receptors, which are not rapidly desensitized by glutamate (Mayer et al. 1989). To investigate this possibility, an inhibitor of NMDA receptors, APV $(50 \mu \mathrm{M})$, was applied along with DHK and MCPG during L-LTP. APV consistently blocked the additional effects of DHK $(N=5)$ (Fig. 6, trace i). Thus, these observations suggest that one function of the increase in GLT-1 during L-LTP is to prevent an ex\pm SEM. cessive activation of mGluRs and NMDA receptors caused by an increase in extracellular glutamate.

\section{An increase in glutamate transport by GLT-1 is required for the induction of additional L-LTP}

Evidence was presented above demonstrating that an increase in glutamate transport was necessary for the expression of L-LTP (Fig. 6). Is an increase of glutamate transport important for the induction of LTP? Naive slices were exposed to DHK and a baseline of the fEPSP was established (50\% of max slope) for $10 \mathrm{~min}$. The slice was then exposed to HFS-1, which induced LTP-1 in the presence of DHK $(N=5)$ (Fig. 7A, DHK, open triangles). For comparison, LTP-1 was also induced in a control group of slices (Fig. 7A, dark circles). The inability of DHK to affect induction of LTP, which was reported previously by Scimemi et al. (2009), was not unexpected because GLT-1 was only at basal levels during induction by HFS- 1 .

Another way to induce LTP is to expose slices to an additional HFS. Frey et al. (1995) showed that a second HFS, HFS-2, could induce additional LTP (LTP-2; $N=5$ ) (Fig. 7B, control, dark circles) when HFS-2 was delivered 3-4 h after HFS-1 (Frey et al. 1995). LTP-2 allowed us to investigate whether an increase in glutamate transport is required for the induction of LTP. Three hours after slices were exposed to HFS- 1 and LTP- 1 was induced, slices were exposed to DHK, and LTP-2 was induced by HFS-2 $(N=5)$ (Fig. $7 \mathrm{~B}, \mathrm{DHK}$, open circles). Under these experimental conditions,

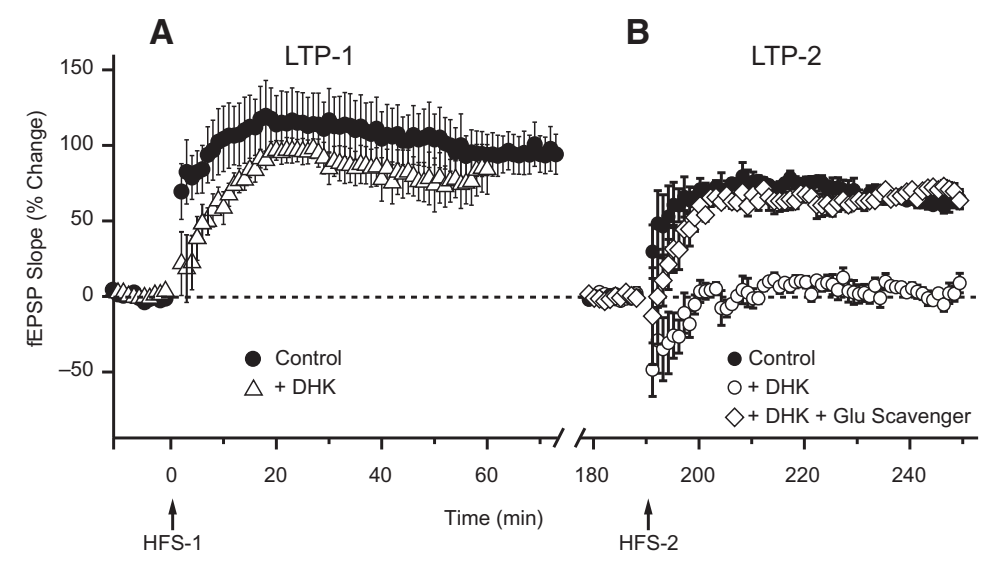

Figure 7. An increase in GLT-1 and glutamate uptake are required for the induction of additional L-LTP. (A) Basal activity of GLT-1 was not required for the induction of LTP-1 by HFS-1. Naive slices were exposed either to HFS-1 or HFS-1 plus DHK after a 10-min baseline was established. The experimental slices were exposed to DHK throughout the entire period of LTP-1. HFS-1 was administered during the time shown under the abscissa of the graph. HFS-1 induced similar LTP-1 in slices treated with (open triangles) and without DHK (closed circles). Thus, basal GLT-1 activity was not required for HFS-1 to elicit LTP-1. (B) "Additional" LTP (LTP-2, control dark circles) can be induced by a second HFS, HFS-2, in hippocampal slices in which LTP-1 had already been induced (Frey et al. 1995). To study the effect of DHK on induction of additional LTP, LTP-1 was induced in slices by HFS- 1 and followed for 180 min, as shown in $A$, control. Then, a new ( $50 \%$ of max amplitude) baseline was established, and the slices received HFS a second time (HFS-2) while exposed to DHK (LTP-2, +DHK, open circles). DHK inhibited the ability of HFS-2 to elicit LTP-2. Since blocking basal GLT-1 activity with DHK did not block the induction of LTP-1 by HFS-1, DHK likely blocked the induction of "additional" LTP, LTP-2, by inhibiting the increase in activity of GLT-1. Therefore, inhibiting GLT-1 would lead to an accumulation of glutamate, which would inhibit the induction of LTP-2. To test this idea, we examined the ability of a glutamate scavenger (glutamic-pyruvic transaminase $[5 \mathrm{U} / \mathrm{mL}]+$ pyruvate [2 mM]) (Overstreet et al. 1997; Min et al. 1998) to rescue the induction of additional LTP from the effect of DHK. The glutamate scavenger rescued the ability of HFS-2 + DHK to induce LTP-2 ( $B$, open diamonds). With the glutamate scavengers present, DHK did not prevent HFS-2 from inducing LTP-2. Thus, DHK appears to inhibit induction of LTP-2 by an accumulation of glutamate, which resulted from inhibition of the increase in glutamate transport. These results demonstrate the importance of the increase in GLT-1 and subsequent glutamate transport for the induction of LTP-2. Error bars are 
DHK inhibited the appearance of LTP-2. Instead of LTP, HFS-2 induced a transient post-tetanic depression in the presence of DHK. This result suggests that the increased activity of GLT-1 and glutamate transport, which would keep extracellular glutamate at low levels, appears to be required for induction of LTP-2. Testing this idea, we found that the inhibition of the ability of HFS-2 to induce additional LTP- 2 by DHK was rescued by treating slices with a glutamate scavenger (glutamic-pyruvic transaminase $[5 \mathrm{U} / \mathrm{mL}]+$ pyruvate $[2 \mathrm{mM}]$ ) while slices were exposed to DHK (Overstreet et al. 1997). In the presence of the glutamate scavenger, HFS-2 was able to induce LTP-2 even though DHK was present (Fig. 7B, +DHK + Glu Scavenger, open diamonds). Thus, DHK appears to inhibit LTP-2 by blocking the increase of GLT-1 and glutamate transport, which would then result in the accumulation of glutamate during the induction of additional LTP-2. It seems noteworthy that when the increase in glutamate uptake was reduced by DHK, not only was HFS unable to generate potentiation, but HFS produced a transient depression. Clearly, such a depression produced by HFS-2 and inhibition of glutamate transport would result in an altered function of neuronal circuitry in the hippocampus.

\section{Discussion}

Changes in synaptic strength such as those that occur during LTP are likely to require several changes in synaptic mechanisms to be stable (Malenka and Bear 2004). Although it has been accepted for some time that basal glutamate uptake is important in various aspects of synaptic transmission, it has only recently become evident that plasticity of glutamate uptake is involved in synaptic plasticities (Levenson et al. 2000, 2002; Pita-Almenar et al. 2006).

The experiments reported here investigate the late phase of the increase in glutamate uptake associated with LTP in the hippocampus. Although astrocytes contain a major amount of the basal GLT-1 in the hippocampus, an increase in GLT-1 activity could occur in cells other than astrocytes (Rothstein et al. 1994; Chen et al. 2002; Furness et al. 2008). We tested the hypothesis that the late increase in glutamate uptake in the hippocampus was due to an increase in glutamate transporter activity in astrocytes. Importantly, CI significantly increased the astrocytic glutamate transporter current over $100 \%$ in hippocampal slices in two separate experiments during L-LTP (Figs. 2C, 3A,B). Furthermore, this result was confirmed by demonstrating that HFS, as well as CI, was able to increase astrocytic transporter current. Therefore, glutamate transporter activity appears to be increased in astrocytes during L-LTP.

The early increase in glutamate uptake is due to an increase of a glutamate transporter (probably neuronal EAAC1), which is insensitive to DHK and not found in astrocytes (Rothstein et al. 1994; He et al. 2000). Consistent with previous studies, we found that the astrocytic glutamate transporter current does not change during E-LTP (Fig. 2C; Diamond et al. 1998; Luscher et al. 1998; Kawamura et al. 2004). In these previous studies, the astrocytic glutamate transporter current was measured only during a time that corresponds to E-LTP. The lack of a change in glutamate transporter current in astrocytes during the early phase of LTP (Fig. 2C) is consistent with the inability of DHK to block the early increase in glutamate uptake (Levenson et al. 2002; Pita-Almenar et al. 2006).

Although CI and HFS increased transporter activity in astrocytes in slices (Figs. 2B, 3), it is possible that cells other than astrocytes (i.e., neurons or oligodendrocytes) are required for the response to $\mathrm{CI}$ and the increase in glutamate transporter activity (Levy et al. 1995; Figiel et al. 2003). To address this, glutamate uptake in cultures of only "mature" astrocytes was investigated. CI significantly increased $\mathrm{Na}^{+}$-dependent glutamate uptake of cultured astrocytes (Fig. 5A,B). Therefore, astrocytes alone can re- spond to CI with an increase in glutamate transporter activity. Although CI can act solely on astrocytes to increase glutamate uptake, is the target of CI the same in slices and cultured astrocytes? Portions of the signaling pathway for increasing glutamate uptake in slices and cultured astrocytes appear to be similar. cAMP mediates the increase in glutamate uptake in both slices and cultured astrocytes, and cellular activity appears to be necessary for cAMP to be effective in both slices and cultured astrocytes (PitaAlmenar et al. 2006). However, future research is required to establish completely the signaling pathway by which GLT-1 is regulated in cultures, in slices, and in vivo. Regardless, observing a large increase in astrocytic glutamate transporter current in slices and an increase in glutamate uptake in cultured astrocytes clearly establishes that a large increase in glutamate uptake occurs in astrocytes during the late phase of LTP.

Which glutamate transporter is responsible for the late increase in glutamate uptake in astrocytes? Previously, we found that DHK blocked the late increase in glutamate uptake in hippocampal slices (Pita-Almenar et al. 2006). Thus, we hypothesized that an increase in GLT-1 was responsible for the increase in glutamate transporter current in slices and also for the increase in glutamate uptake in cultured astrocytes. This hypothesis was tested in three ways. First, we found that DHK inhibited the CI-induced increase in astrocytic transporter current in slices (Fig. 3). Second, DHK inhibited the CI-induced increase in glutamate uptake in cultured astrocytes (Fig. 5). Third, in cultured astrocytes, CI increased the amount of GLT-1 in plasma membrane protein (Fig. 5D). The increase of GLT-1 in astrocytes $(97 \%)$ (Fig. 5D) was very similar to the increase in glutamate uptake of cultured astrocytes (109\%) (Fig. 5A). The increase in the amount of GLT-1 in the plasma membrane directly confirms the experiments using DHK to inhibit GLT-1. In addition, the results of the experiments (Fig. 5) measuring increases in GLT-1 in cultured astrocytes were confirmed by Western blots from slices (Pita-Almenar et al. 2006). Taken all together, these results demonstrate that an increase in GLT-1 was responsible for the late increase in glutamate uptake in astrocytes.

Some processes of presynaptic terminals in the hippocampus contain GLT-1 (Chen et al. 2004). Is the entire late increase in glutamate uptake in the hippocampus due to an increase of GLT-1 in astrocytes? First, changes in levels of GLAST or EAAC1 do not seem to contribute to the late increase in glutamate uptake (Fig. 5; Pita-Almenar et al. 2006). Second, DHK inhibited the entire increase in glutamate uptake, indicating that the increase in transporter activity was entirely due to GLT-1 (Figs. 3, 5B, present paper; Figs. 4B, 6 in Pita-Almenar et al. 2006). Third, the change in GLT-1 in astrocytes was large enough to account for the change in glutamate uptake in slices. The best estimate of the change in GLT-1 in astrocytes comes from Figure 3. The change in DHK-sensitive astrocytic glutamate transporter current was $254 \%$. If we assume that glutamate uptake in astrocytes of the hippocampus was responsible for $60 \%$ of the total glutamate uptake (Rothstein et al. 1994) and that the remaining $40 \%$ of glutamate uptake in cells other than astrocytes did not exhibit a change in GLT-1, then the calculated increase in overall hippocampal glutamate uptake is $152 \%$. Thus, the $254 \%$ change in glutamate transporter activity in astrocytes is adequate to account for the largest changes in glutamate uptake and transporter current that we observed, e.g., $128 \%$ (Fig. 1B), 144\% (Fig. 2C), and 127\% (Fig. 3). It is still possible that GLT-1 activity increased in nonastrocytic processes, but such a contribution from nonastrocytic GLT-1 would be small. All our results support the hypothesis that the late increase in glutamate uptake in the hippocampus is due to an increase in GLT-1 in astrocytes.

The use of the CI analog in the above experiments was validated in numerous ways. CI produced LTP in slices and an increase 
in $\mathrm{Na}^{+}$-dependent glutamate uptake in slices during early and late LTP (Fig. 1). CI produced a change (as did HFS) in transporter current during L-LTP but not E-LTP. This result correlates with the ability of HFS to increase DHK-dependent glutamate uptake during L-LTP but not E-LTP. CI was specific, as forskolin alone did not induce an increase in glutamate uptake, and only brief treatments of forskolin $+0 \mathrm{Mg}^{2+}(20 \mathrm{~min})$ were required for CI to be effective. We confirmed that HFS (as well as CI) could increase the transporter current in astrocytes in hippocampal slices. Importantly, the studies on the function of increases in glutamate uptake (Figs. 6, 7) were all performed using HFS. The increase of glutamate uptake during LTP is a very robust phenomenon triggered by a variety of stimuli in a broad array of systems across different levels of organization. This robustness of the phenomenon suggests that the increase in glutamate uptake during LTP will also exist in vivo.

The increase in glutamate uptake that occurs in the hippocampus is closely correlated with LTP (Levenson et al. 2002; Pita-Almenar et al. 2006). This connection of LTP and glutamate uptake suggests that the increase in glutamate uptake has an important role for LTP. Thus, we tested the hypothesis that the increase in glutamate uptake due to GLT-1 was important for the expression and induction of LTP. LTP was elicited by HFS in both the expression and induction types of experiments. DHK inhibition of basal GLT-1 activity during baseline control had only a small effect on fEPSPs. However, DHK inhibition of the increase in glutamate uptake during late LTP reversibly decreased the expression of LTP (Fig. 6, trace d). Therefore, the increase in glutamate uptake due to the increase in GLT-1 was necessary for the expression of late LTP.

In the hippocampus, evidence suggests both postsynaptic and presynaptic changes are involved in LTP (Kerchner and Nicoll 2008; Enoki et al. 2009; Lisman 2009). Indeed, a slowly developing increase in glutamate release during L-LTP has been visualized using fluorescent dyes or mice expressing SynaptopHluorin in presynaptic boutons (Zakharenko et al. 2001; Bayazitov et al. 2007). The simplest explanation for elimination of expression of late LTP by DHK is that glutamate accumulated and subsequently inhibited expression of LTP by increased desensitization of AMPA receptors and/or excessive activation of metabotropic and NMDA receptors. In fact, removal of extracellular glutamate or inhibition of both metabotropic glutamate receptors and NMDA receptors eliminated the effect of DHK on expression of late LTP (Fig. 6). Thus, the increase in GLT-1 during the late phase of LTP appears to be, at least in part, important to prevent an excessive activation of mGluRs and NMDA receptors when release of glutamate is increased. A late increase in GLT-1 activity appears to be needed to compensate for an increase in release of glutamate that causes an enhanced activation of glutamate receptors during late LTP (Zakharenko et al. 2001; Bayazitov et al. 2007; Enoki et al. 2009).

The importance of the increase in glutamate uptake for the induction of LTP was also tested. Inhibition of basal glutamate uptake during HFS did not affect the induction of LTP (Fig. 7A) since the increase in GLT-1 activity does not occur until a few hours after induction of LTP (Pita-Almenar et al. 2006). An additional LTP (LTP-2) can be induced by exposing the slice to a second HFS (HFS-2) 3-4 h after the first HFS (Fig. 7B, control; Frey et al. 1995). When DHK was present during the induction of LTP-2 by HFS-2, DHK abolished the induction of additional LTP (Fig. 7B, $\mathrm{DHK})$. Because the presence of a glutamate scavenger rescued the ability of HFS-2 to induce additional LTP, the inability of HFS- 2 to elicit additional LTP in the presence of DHK was due to elevation of glutamate during HFS-2 (Fig. 7B). Thus, an increase in glutamate uptake is required for HFS- 2 to induce additional LTP. This experiment may be considered a model of a second memory event (HFS-2) that follows an earlier memory event (HFS-1). Since memories are often formed in sequences, it seems reasonable to suggest that regulation of glutamate uptake is essential for the formation of sequential memories (Wang and Morris 2010).

An increase in glutamate transport, most likely in astrocytes, is important for both the expression of LTP and some forms of the induction of LTP. It is likely that heightened glutamate transport plays an important, ongoing role in the ability of hippocampal circuitry to code and store information. If this is true, the ability to form and express some types of memories will depend upon the healthiness of the plasticity of glutamate transport. It is also likely that the regulation of glutamate uptake plays a role in many processes in addition to memory formation (e.g., addiction, stress, and seizure prevention) (Yang et al. 2005; Willmore and Ueda 2009; Reissner and Kalivas 2010). Equally likely, abnormalities in the plasticity of glutamate uptake will be found to underlie several pathologies of brain function (e.g., epilepsy, ALS, Alzheimer's disease, HIV-1-associated dementia, and Huntington's disease) (Maragakis and Rothstein 2001; Benarroch 2010; Mookherjee et al. 2011).

\section{Materials and Methods}

\section{Hippocampal slices}

Transverse hippocampal slices $(400 \mu \mathrm{m})$ were obtained from male (100-150 g) Sprague-Dawley rats (Harlan, Indianapolis, IN), according to protocols approved by the University of Houston Institutional Animal Care and Use Committee. Slices were cut in ice-cold "cutting" solution $(110 \mathrm{mM}$ sucrose, $60 \mathrm{mM}$ $\mathrm{NaCl}, 3 \mathrm{mM} \mathrm{KCl}, 1.25 \mathrm{mM} \mathrm{NaH} \mathrm{PO}_{4}, 28 \mathrm{mM} \mathrm{NaHCO} 3,5 \mathrm{mM}$ D-glucose, $0.5 \mathrm{mM} \mathrm{CaCl}_{2}, 7 \mathrm{mM} \mathrm{MgCl}_{2}$, and $0.6 \mathrm{mM}$ ascorbate) saturated with $95 \% \mathrm{O}_{2}$ and $5 \% \mathrm{CO}_{2}$. After $1 \mathrm{~h}$ of recovery in $50 \%$ cutting solution and $50 \%$ artificial cerebrospinal fluid (ACSF: $125 \mathrm{mM} \mathrm{NaCl}, 2.5 \mathrm{mM} \mathrm{KCl}, 1.25 \mathrm{mM} \mathrm{NaH}_{2} \mathrm{PO}_{4}, 25 \mathrm{mM}$ $\mathrm{NaHCO}_{3}, 25 \mathrm{mM}$ D-glucose, $2 \mathrm{mM} \mathrm{CaCl}_{2}$, and $1 \mathrm{mM} \mathrm{MgCl}_{2}$ saturated with $95 \% \mathrm{O}_{2}$ and $5 \% \mathrm{CO}_{2}$ ) at room temperature, slices were incubated for $30 \mathrm{~min}$ in $100 \%$ ACSF at room temperature. Then, slices were placed in an interface chamber (Fine Science Tools), perfused at a flow rate of $1 \mathrm{~mL} / \mathrm{min}$ with ACSF, and maintained at $32^{\circ} \mathrm{C}$. Half of the slices $(6-10$ slices total per rat) were experimentals, and the other half of the slices were controls. Before recording, slices were equilibrated in the recording chamber for $30 \mathrm{~min}$.

\section{Extracellular field potentials}

The strength of synaptic communication was determined by measuring the initial slope of the excitatory postsynaptic field potentials (fEPSP) in an interface chamber. Borosilicate glass recording electrodes were filled with ACSF and had resistances of 1-5 M . Stimulating electrodes were placed in the stratum radiatum of CA1 next to area CA3, and the recording electrodes were placed in the stratum radiatum of area CA1. Recording electrodes were introduced $\sim 100 \mu \mathrm{m}$ into the slice. Electrical stimulation of $100-300 \mu \mathrm{A}$ for $100 \mu \mathrm{sec}$ was applied using a bipolar tungsten $(10-\mu \mathrm{m}$ diameter) isonel-coated wire (A-M Systems analog stimulus isolator). Recordings of extracellular field potentials were amplified using an A-M Systems Neuroprobe amplifier low-pass filtered at $1 \mathrm{kHz}$ (low-pass Bessel four-pole), digitized at $5 \mathrm{kHz}$, and analyzed using Molecular Devices software (Digidata 1322A, Clampex 8.2, and Clampfit 8.2; Molecular Devices). Stimulus intensities for recording baseline fEPSPs were adjusted to have slopes that were $50 \%$ of the maximum. Field potentials were recorded at 1-min intervals. The health of the slice was monitored by continuously recording extracellular field potentials throughout experiments. Additional details of recording field potentials have been previously described (Pita-Almenar et al. 2006). 


\section{Induction of LTP}

As previously shown (Otmakhov et al. 2004), LTP was induced chemically in experimental slices by applying forskolin $(50 \mu \mathrm{M})$ in DMSO (0.01\%) and $0 \mathrm{Mg}^{2+}$ ACSF for $20 \mathrm{~min}$. ACSF + DMSO was applied to control slices for $20 \mathrm{~min}$. To confirm the induction of LTP, field potentials were recorded from one out of each group of slices from a given animal. In several experiments, LTP was induced electrically (HFS, high-frequency stimulation) using two trains of $100-\mathrm{Hz}$ pulses (50\% max) separated by $20 \mathrm{sec}$ (PitaAlmenar et al. 2006). To induce "additional" LTP, a new baseline (50\% max) was obtained 180 min after the initial HFS (HFS-1). After 10 min of baseline recording, the second HFS (HFS-2) using the new baseline was applied. The potentiation of the responses was followed for another 60 min after HFS-2 was administered.

\section{Flash photolysis evoked glutamate transporter current in astrocytes}

Slices were placed in a submerged chamber maintained at $32^{\circ} \mathrm{C}$. Cells were visualized using infrared-illuminated, differential interference contrast optics (BX50WI; Olympus Optical) and a Newvicon camera (DAGE-MTI). Whole-cell recordings were made with an Axopatch 1D amplifier (Molecular Devices). Astrocytes in the CA1 stratum radiatum were identified by their small cell bodies, low input resistance $(10-60 \mathrm{M} \Omega)$, and negative resting membrane potentials $(\sim-80 \mathrm{mV})$. During transporter current measurements, the clamp potential was set at the astrocyte resting potential. Cells that did not have low input resistances and hyperpolarized membrane potentials were excluded from the analysis (Matthias et al. 2003). Whole-cell recordings were low-pass filtered at $2 \mathrm{kHz}$ (eight-pole Bessel) and digitized at $10 \mathrm{kHz}$. Data were digitized at 16-bit resolution (ITC18; Instrutech) and stored. Glass pipette electrodes (5-7 M $\Omega$ ) for recording whole-cell currents were made from Warner Instruments glass. The pipette solution contained $140 \mathrm{mM} \mathrm{KMeSO}_{4}, 10 \mathrm{mM}$ HEPES, $1 \mathrm{mM}$ EGTA, $4 \mathrm{mM} \mathrm{NaCl}, 0.28 \mathrm{mM} \mathrm{CaCl}_{2}, 4 \mathrm{mM} \mathrm{Mg}_{2}$-ATP, $0.3 \mathrm{mM}$ Tris-GTP, and $14 \mathrm{mM}$ phosphocreatine (pH 7.3).

4-Methoxy-7-nitroindolinyl-caged L-glutamate (MNI-glutamate) was superfused through the recording chamber at a concentration of $100 \mu \mathrm{M}$ and uncaged using a mercury lamp (ULH100H6; Olympus Optical) connected to the epi-illumination pathway of the microscope. The lamp output was set to maximum, and the entire back aperture of the $40 \times$ objective was illuminated with 10-msec flashes using a fast electronic shutter (UniBlitz). During whole-cell recordings, AMPA and kainate receptors were blocked with DNQX $(20 \mu \mathrm{M})$, NMDA receptors were blocked with APV $(50 \mu \mathrm{M})$ and MK801 $(20 \mu \mathrm{M})$, and $\mathrm{Na}^{+}$ channels were blocked with TTX $(0.1 \mu \mathrm{M})$. Rapid uncaging of glutamate by the 10-msec UV light flash induced an inward current showing voltage-dependence and inward rectification characteristic of glutamate transporter currents (Bergles et al. 2002). The peak amplitude of 10 consecutive traces recorded every $20 \mathrm{sec}$ was averaged to quantify the glutamate-induced transporter current for each cell. One to four cells were recorded from each control and experimental slice. The means of the transporter currents from paired experimental and control slices were used in the analysis.

\section{Glutamate uptake}

For each experiment, one experimental and one control slice were separately incubated during the early or late time domains of LTP and submerged in an oxygenated chamber, at $32^{\circ} \mathrm{C}$, containing labeling-ACSF as described in Pita-Almenar et al. (2006). Labeling-ACSF consisted of ACSF plus radiolabeled glutamate $\left(4 \mu \mathrm{M}\right.$ cold glutamate $+1 \mu \mathrm{M}$ radioactive glutamate, $\mathrm{L}-\left[{ }^{14} \mathrm{C}\right.$ (U)]-glutamic acid, $250 \mu \mathrm{Ci} / \mu \mathrm{mol}$; Perkin Elmer). The incubation time with glutamate was $7.5 \mathrm{~min}$, which was within the linear range of uptake. The absolute number of counts incorporated varied from 700 to 2000 DPM with a background of 20 DPM. After incubation, slices were rinsed with cold ACSF, blotted, and frozen on dry ice. Area CA1 was dissected and solubilized in 1\% SDS. Uptake was calculated using the specific radioactivity of the
labeling-ACSF and normalized to total protein and time of incubation. Glutamate uptake was expressed as percent change in uptake of experimental slices compared to control slices.

\section{Cultures of hippocampus astrocytes}

The procedure for making cultures of astrocytes followed the protocol of Engele's lab (Schluter et al. 2002; Lehmann et al. 2009). Hippocampi from 2-d-old neonatal rat pups were dissociated into a cell suspension using mechanical digestion. Cells were plated in tissue culture flasks at a concentration of $1.5 \times 10^{6}$ cells per plate. Cells were incubated in DMEM/F12 (D8437; Sigma-Aldrich) modified medium (10\% fetal bovine serum, $1 \%$ penicillin and streptomycin, $2.5 \mu \mathrm{g} / \mathrm{mL}$ fungizone) at $37^{\circ} \mathrm{C}$ in a moist $5 \% \mathrm{CO}_{2}$, $95 \%$ air atmosphere. At the end of $48-72 \mathrm{~h}$, cells adhered and began multiplying. The medium was then changed every $48-$ $72 \mathrm{~h}$. After incubation for 7-9 d, flasks were shaken at $260 \mathrm{rpm}$ for $18-20 \mathrm{~h}$ to remove other cell types. After this time, the amplified cultures were incubated in serum-free DMEM/F12 $(20 \mathrm{ng} / \mathrm{mL}$ basic fibroblast growth factor) with N2 medium supplement (Invitrogen) for an additional 3-5 d. After this time, the amplified cultures were frozen and stored in liquid nitrogen. Before experiments, cultures were incubated in serum-free DMEM/F12 (20 ng/mL basic fibroblast growth factor) with N2 medium supplement (Invitrogen) for 3-5 additional days.

\section{Cell staining}

Cultures of hippocampal astrocytes were fixed with $4 \%$ paraformaldehyde in PBS-buffer for $10 \mathrm{~min}$ and permeabilized with $1 \%$ Triton in PBS-buffer. Upon blocking nonspecific binding with $5 \%$ normal goat serum in PBS for $1 \mathrm{~h}$, cultures were incubated overnight at $4^{\circ} \mathrm{C}$ with primary antibodies: a rabbit anti-glial fibrillary acidic protein (GFAP) antibody (dilution 1:100; Abcam), a guinea pig anti-GLT-1 antibody (dilution 1:1000; Millipore), a guinea pig GLAST antibody (dilution 1:1000; Millipore), or a rabbit anti-EAAC1 antibody (dilution 1:100; Abcam). Antibody labeling was detected by Alexa 488- or Alexa 568-labeled secondary antibodies (Invitrogen). Cultures were additionally stained with DAPI (dilution 1:5000; Sigma-Aldrich). Images were collected on an FV-1000 confocal microscope (Olympus) with filter settings corresponding to Alexa 488 or Alexa 568.

\section{Cell surface biotinylation assays}

Cell surface biotinylation was performed by treating cultured hippocampal astrocytes with sulfosuccinimidyl 2-(biotinamido)ethyl-1,3-dithiopropionates $(1 \mathrm{mg} / \mathrm{mL}$ in PBS buffer; Thermo Scientific) for $30 \mathrm{~min}$ on ice with gentle shaking. Ice-cold PBS buffer containing $100 \mathrm{mM}$ glycine was then added to stop the reaction. After an additional 20 min of incubation, the cells were collected and lysed by gentle trituration in PBS containing $1 \%$ Triton X-100. The biotinylated proteins from the cell surface were recovered from the lysates by incubation with immobilized streptavidin-agarose beads (Pierce Biotechnology). Bound proteins were eluted from the beads in Laemmli buffer, and a portion of the original lysate was also saved for total protein analysis. Total proteins were then separated on SDS-PAGE and transferred to nitrocellulose. We have previously observed that boiling or heating samples after addition of Laemmli buffer induced the formation of dimer/trimer bands of transporters. Thus, we avoided the boiling step in our experiments. The proteins were detected by immunoblot with anti-GLT-1 (dilution 1:3000; Millipore) or anti-GLAST (dilution 1:1000; Millipore), and protein bands were visualized with ECL. Immunoreactivity was quantified using a Gel-Pro analyzer (Media Cybernetics Inc.). Actin immunoreactivity (anti-Actin, dilution 1:100; Santa Cruz Biotechnology) was used as a loading control in experiments on total protein.

\section{Drugs and solutions used}

4-Methoxy-7-nitroindolinyl-caged L-glutamate (MNI-glutamate), 6,7-dinitroquinoxaline-2,3-dione (DNQX), DL-2-amino-5-phosphonopentanoic acid (APV), $(5 S, 10 R)-(+)-5$-Methyl- 10, 
11-dihydro- 5H-dibenzo[a,d]cyclohepten- 5,10 -imine maleate (MK801), tetrodotoxin (TTX), forskolin, dihydrokainate (DHK), DL-threo-beta-benzyloxyaspartic acid (TBOA), and (RS)- $\alpha$ Methyl-4-carboxyphenylglycine (RS-MCPG) were obtained from TOCRIS. Glutamic-pyruvic transaminase (GPT) and sodium pyruvate were obtained from Sigma-Aldrich. GPT was dialyzed for $>3 \mathrm{~h}$ using a Slide-A-Lyzer cassette with a 10-kDa cutoff (Pierce Chemical). Forskolin was dissolved in dimethyl sulfoxide (DMSO) as a stock solution. The DMSO concentration used in experiments was $<0.01 \%$. The stocks for the other drugs were prepared in water. In $\mathrm{Mg}^{2+}$-free treatments, $\mathrm{MgCl}_{2}$ was omitted from the ACSF. $\mathrm{Na}^{+}$-free solutions were prepared with $125 \mathrm{mM}$ choline chloride $\left(\mathrm{C}_{5} \mathrm{H}_{14} \mathrm{ONCl}\right), 10 \mathrm{mM}$ HEPES, $2.5 \mathrm{mM} \mathrm{KCl}$, $25 \mathrm{mM}$ D-glucose, $2 \mathrm{mM} \mathrm{CaCl}_{2}$, and $1 \mathrm{mM} \mathrm{MgCl}_{2}$.

\section{Statistical analysis}

Data are expressed as mean \pm SEM. Glutamate uptake was measured in the CA1 regions of three experimental and three control slices per rat. Each group of three slices was exposed to label in the same container, and uptake was analyzed from the group. Paired $t$-tests were used to analyze significance. " $\mathrm{N}$ " reports the number of animals used in an experiment measuring glutamate uptake. In the experiments measuring transporter currents, currents were measured from several astrocytes in each slice, and usually three experimental and three control slices were used per animal. Typically, slices from 3-6 animals were used in an experiment. In these experiments, " $\mathrm{N}$ " reports the total number of astrocytes that were recorded. One-way ANOVA or Student's $t$-tests were used to analyze the significance of the difference between groups. Data were analyzed using Prism 4 for Macintosh (GraphPad Software, Inc.).

\section{Acknowledgments}

We thank Dr. Jokubas Ziburkus and Claudia Alvarez-Baron for helpful discussions and comments on the manuscript and Crystal Malone for major help with preparation of the manuscript. This work was supported by NIH grant NS28462 to A.E.

\section{References}

Bayazitov IT, Richardson RJ, Fricke RG, Zakharenko SS. 2007. Slow presynaptic and fast postsynaptic components of compound long-term potentiation. J Neurosci 27: 11510-11521.

Benarroch EE. 2010. Glutamate transporters: Diversity, function, and involvement in neurologic disease. Neurology 74: 259-264.

Berger UV, DeSilva TM, Chen W, Rosenberg PA. 2005. Cellular and subcellular mRNA localization of glutamate transporter isoforms GLT1a and GLT1b in rat brain by in situ hybridization. J Comp Neurol 492: $78-89$.

Bergles DE, Jahr CE. 1997. Synaptic activation of glutamate transporters in hippocampal astrocytes. Neuron 19: 1297-1308.

Bergles DE, Tzingounis AV, Jahr CE. 2002. Comparison of coupled and uncoupled currents during glutamate uptake by GLT-1 transporters. J Neurosci 22: 10153-10162.

Boehm J, Kang MG, Johnson RC, Esteban J, Huganir RL, Malinow R. 2006 Synaptic incorporation of AMPA receptors during LTP is controlled by a PKC phosphorylation site on GluR1. Neuron 51: 213-225.

Bolshakov VY, Golan H, Kandel ER, Siegelbaum SA. 1997. Recruitment of new sites of synaptic transmission during the cAMP-dependent late phase of LTP at CA3-CA1 synapses in the hippocampus. Neuron 19: 635-651.

Chen W, Aoki C, Mahadomrongkul V, Gruber CE, Wang GJ, Blitzblau R, Irwin N, Rosenberg PA. 2002. Expression of a variant form of the glutamate transporter GLT1 in neuronal cultures and in neurons and astrocytes in the rat brain. J Neurosci 22: 2142-2152.

Chen W, Mahadomrongkul V, Berger UV, Bassan M, DeSilva T, Tanaka K, Irwin N, Aoki C, Rosenberg PA. 2004. The glutamate transporter GLT1a is expressed in excitatory axon terminals of mature hippocampal neurons. J Neurosci 24: 1136-1148.

Conti F, DeBiasi S, Minelli A, Rothstein JD, Melone M. 1998. EAAC1, a high-affinity glutamate transporter, is localized to astrocytes and gabaergic neurons besides pyramidal cells in the rat cerebral cortex. Cereb Cortex 8: 108-116.

Danbolt NC. 2001. Glutamate uptake. Prog Neurobiol 65: 1-105.
Danbolt NC, Storm-Mathisen J, Kanner BI. 1992. An [Na++K+]coupled L-glutamate transporter purified from rat brain is located in glial cell processes. Neuroscience 51: 295-310.

Diamond JS, Bergles DE, Jahr CE. 1998. Glutamate release monitored with astrocyte transporter currents during LTP. Neuron 21: 425-433.

Enoki R, Hu YL, Hamilton D, Fine A. 2009. Expression of long-term plasticity at individual synapses in hippocampus is graded, bidirectional, and mainly presynaptic: Optical quantal analysis. Neuron 62: $242-253$

Figiel M, Maucher T, Rozyczka J, Bayatti N, Engele J. 2003. Regulation of glial glutamate transporter expression by growth factors. Exp Neurol 183: $124-135$.

Franke B, Figiel M, Engele J. 1998. CNS glia are targets for GDNF and neurturin. Histochem Cell Biol 110: 595-601.

Frey U, Schollmeier K, Reymann KG, Seidenbecher T. 1995. Asymptotic hippocampal long-term potentiation in rats does not preclude additional potentiation at later phases. Neuroscience 67: 799-807.

Furness DN, Dehnes Y, Akhtar AQ, Rossi DJ, Hamann M, Grutle NJ, Gundersen V, Holmseth S, Lehre KP, Ullensvang K, et al. 2008. A quantitative assessment of glutamate uptake into hippocampal synaptic terminals and astrocytes: New insights into a neuronal role for excitatory amino acid transporter 2 (EAAT2). Neuroscience 157: 80-94.

He Y, Janssen WG, Rothstein JD, Morrison JH. 2000. Differential synaptic localization of the glutamate transporter EAAC1 and glutamate receptor subunit GluR2 in the rat hippocampus. J Comp Neurol 418: $255-269$.

Huang YH, Bergles DE. 2004. Glutamate transporters bring competition to the synapse. Curr Opin Neurobiol 14: 346-352.

Huang YH, Sinha SR, Tanaka K, Rothstein JD, Bergles DE. 2004. Astrocyte glutamate transporters regulate metabotropic glutamate receptor-mediated excitation of hippocampal interneurons. J Neurosci 24: $4551-4559$.

Katagiri H, Tanaka K, Manabe T. 2001. Requirement of appropriate glutamate concentrations in the synaptic cleft for hippocampal LTP induction. Eur I Neurosci 14: 547-553.

Kawamura Y, Manita S, Nakamura T, Inoue M, Kudo Y, Miyakawa H. 2004. Glutamate release increases during mossy-CA3 LTP but not during Schaffer-CA1 LTP. Eur J Neurosci 19: 1591-1600.

Kerchner GA, Nicoll RA. 2008. Silent synapses and the emergence of a postsynaptic mechanism for LTP. Nat Rev Neurosci 9: 813-825.

Kopec CD, Li B, Wei W, Boehm J, Malinow R. 2006. Glutamate receptor exocytosis and spine enlargement during chemically induced long-term potentiation. J Neurosci 26: 2000-2009.

Lehmann C, Bette S, Engele J. 2009. High extracellular glutamate modulates expression of glutamate transporters and glutamine synthetase in cultured astrocytes. Brain Res 1297: 1-8.

Levenson J, Endo S, Kategaya LS, Fernandez RI, Brabham DG, Chin J, Byrne JH, Eskin A. 2000. Long-term regulation of neuronal high-affinity glutamate and glutamine uptake in Aplysia. Proc Natl Acad Sci 97: 12858-12863.

Levenson J, Weeber E, Selcher JC, Kategaya LS, Sweatt JD, Eskin A. 2002. Long-term potentiation and contextual fear conditioning increase neuronal glutamate uptake. Nat Neurosci 5: 155-161.

Levy LM, Lehre KP, Walaas SI, Storm-Mathisen J, Danbolt NC. 1995. Down-regulation of glial glutamate transporters after glutamatergic denervation in the rat brain. Eur J Neurosci 7: 2036-2041.

Liao D, Jones A, Malinow R. 1992. Direct measurement of quantal changes underlying long-term potentiation in CA1 hippocampus. Neuron 9: 1089-1097.

Lisman JE. 2009. The pre/post LTP debate. Neuron 63: 281-284.

Luscher C, Malenka RC, Nicoll RA. 1998. Monitoring glutamate release during LTP with glial transporter currents. Neuron 21: 435-441.

Malenka RC, Bear MF. 2004. LTP and LTD: An embarrassment of riches. Neuron 44: 5-21.

Maleszka R, Helliwell P, Kucharski R. 2000. Pharmacological interference with glutamate re-uptake impairs long-term memory in the honeybee, Apis mellifera Behav Brain Res 115: 49-53.

Maragakis NJ, Rothstein JD. 2001. Glutamate transporters in neurologic disease. Arch Neurol 58: 365-370.

Matthias K, Kirchhoff F, Seifert G, Huttmann K, Matyash M, Kettenmann H, Steinhauser C. 2003. Segregated expression of AMPA-type glutamate receptors and glutamate transporters defines distinct astrocyte populations in the mouse hippocampus. J Neurosci 23: $1750-1758$.

Mayer ML, Vyklicky L Jr, Clements J. 1989. Regulation of NMDA receptor desensitization in mouse hippocampal neurons by glycine. Nature 338: $425-427$.

Min MY, Rusakov DA, Kullmann DM. 1998. Activation of AMPA, kainate, and metabotropic receptors at hippocampal mossy fiber synapses: Role of glutamate diffusion. Neuron 21: 561-570.

Mookherjee P, Green PS, Watson GS, Marques MA, Tanaka K, Meeker KD, Meabon JS, Li N, Zhu P, Olson VG, et al. 2011. GLT-1 loss accelerates 
cognitive deficit onset in an Alzheimer's disease animal model. J Alzheimers Dis 26: 447-455.

Omrani A, Melone M, Bellesi M, Safiulina V, Aida T, Tanaka K, Cherubini E, Conti F. 2009. Up-regulation of GLT-1 severely impairs LTD at mossy fibre-CA3 synapses. J Physiol 587: 4575-4588.

Otmakhov N, Khibnik L, Otmakhova N, Carpenter S, Riahi S, Asrican B, Lisman J. 2004. Forskolin-induced LTP in the CA1 hippocampal region is NMDA receptor dependent. J Neurophysiol 91: 1955-1962.

Overstreet LS, Pasternak JF, Colley PA, Slater NT, Trommer BL. 1997. Metabotropic glutamate receptor mediated long-term depression in developing hippocampus. Neuropharmacology 36: 831-844.

Pita-Almenar JD, Collado MS, Colbert CM, Eskin A. 2006. Different mechanisms exist for the plasticity of glutamate reuptake during early long-term potentiation (LTP) and late LTP. J Neurosci 26: 10461-10471.

Reissner KJ, Kalivas PW. 2010. Using glutamate homeostasis as a target for treating addictive disorders. Behav Pharmacol 21: 514-522.

Rothstein JD, Martin L, Levey AI, Dykes-Hoberg M, Jin L, Wu D, Nash N, Kuncl RW. 1994. Localization of neuronal and glial glutamate transporters. Neuron 13: $713-725$.

Schlag BD, Vondrasek JR, Munir M, Kalandadze A, Zelenaia OA, Rothstein JD, Robinson MB. 1998. Regulation of the glial $\mathrm{Na}+$-dependent glutamate transporters by cyclic AMP analogs and neurons. Mol Pharmacol 53: 355-369.

Schluter K, Figiel M, Rozyczka J, Engele J. 2002. CNS region-specific regulation of glial glutamate transporter expression. Eur J Neurosci 16: 836-842.

Scimemi A, Tian H, Diamond JS. 2009. Neuronal transporters regulate glutamate clearance, NMDA receptor activation, and synaptic plasticity in the hippocampus. J Neurosci 29: 14581-14595.

Shen Y, Linden DJ. 2005. Long-term potentiation of neuronal glutamate transporters. Neuron 46: 715-722.
Sokolov MV, Rossokhin AV, Astrelin AV, Frey JU, Voronin LL. 2002. Quantal analysis suggests strong involvement of presynaptic mechanisms during the initial $3 \mathrm{~h}$ maintenance of long-term potentiation in rat hippocampal CA1 area in vitro. Brain Res 957: 61-75.

Stout C, Charles A. 2003. Modulation of intercellular calcium signaling in astrocytes by extracellular calcium and magnesium. Glia 43: 265-273.

Tzingounis AV, Wadiche JI. 2007. Glutamate transporters: Confining runaway excitation by shaping synaptic transmission. Nat Rev Neurosci 8: $935-947$.

Wang SH, Morris RG. 2010. Hippocampal-neocortical interactions in memory formation, consolidation, and reconsolidation. Annu Rev Psychol 61: 49-79.

Willmore LJ, Ueda Y. 2009. Posttraumatic epilepsy: Hemorrhage, free radicals and the molecular regulation of glutamate. Neurochem Res 34: $688-697$.

Yang CH, Huang CC, Hsu KS. 2005. Behavioral stress enhances hippocampal CA1 long-term depression through the blockade of the glutamate uptake. J Neurosci 25: 4288-4293.

Zakharenko SS, Zablow L, Siegelbaum SA. 2001. Visualization of changes in presynaptic function during long-term synaptic plasticity. Nat Neurosci 4: $711-717$.

Zho WM, You JL, Huang CC, Hsu KS. 2002. The group I metabotropic glutamate receptor agonist (S)-3,5-dihydroxyphenylglycine induces a novel form of depotentiation in the CA1 region of the hippocampus. J Neurosci 22: 8838-8849.

Zou S, Pita-Almenar JD, Eskin A. 2011. Regulation of glutamate transporter GLT-1 by MAGI-1. J Neurochem 117: 833-840.

Received June 27, 2011; accepted in revised form September 18, 2012. 


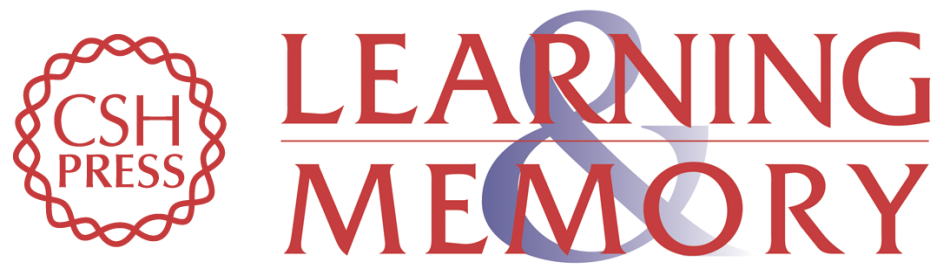

\section{Relationship between increase in astrocytic GLT-1 glutamate transport and late-LTP}

Juan D. Pita-Almenar, Shengwei Zou, Costa M. Colbert, et al.

Learn. Mem. 2012, 19:

Access the most recent version at doi:10.1101//m.023259.111

References This article cites 58 articles, 14 of which can be accessed free at:

http://learnmem.cshlp.org/content/19/12/615.full.html\#ref-list-1

License

Email Alerting Receive free email alerts when new articles cite this article - sign up in the box at the Service top right corner of the article or click here. 